\title{
Influence of Prolactin Administration on the Ultimobranchial Body and Parathyroid Glands of the Freshwater Snake, Natrix piscator
}

\author{
By \\ Ajai Kumar SRIVASTAV ${ }^{1}$, Ladli RANI ${ }^{1}$ and Yuichi SASAYAMA ${ }^{2}$ \\ ${ }^{1}$ Department of Zoology, University of Gorakhpur, Gorakhpur-273 009, India \\ ${ }^{2}$ Department of Biology, Faculty of Science, Toyama University, Toyama 930, Japan \\ - Received for Publication, February 14, 1994-
}

Key Words: Prolactin, Ultimobranchial Body, Parathyroid, Serum Calcium, Freshwater Snake

Summary: The effects of ovine prolactin $(10 \mathrm{I} . \mathrm{U} . / 100 \mathrm{~g}$ body wt) on the ultimobranchial body and parathyroid glands were investigated in Natrix piscator for 15 days. The ultimobranchial body of the prolactin treated specimens depicts signs of increased activity whereas the parathyroid glands exhibit reduced activity.

Several publications exist regarding the hypercalcemic effect of prolactin in fishes (Olivereau and Olivereau, 1970, 1978; Pang et al., 1978; Pang, 1981; Wendelaar Bonga and Flik, 1982, 1984; Flik et al., 1986), but there are few reports for tetrapods amphibia (Baksi et al., 1978; Srivastav and Rani, 1991a), reptile (Swarup et al., 1985; Srivastav and Rani, 1990), bird (Baksi et al., 1978) and mammal (Robinson et al., 1975). In the present study an attempt has been made to investigate the effect of prolactin on the ultimobranchial body (UBB) and parathyroid gland of the freshwater snake, Natrix piscator as there exists no information from reptile regarding the activity of these glands in response to prolactin administration. The activity of ultimobranchial body and parathyroid gland has been judged by the staining response and nuclear volume. The increased nuclear size/area/volume has been considered as indications for the hyperactivity of various endocrine glands (Olivereau and Olivereau, 1978, 1982; Olivereau et al., 1982, 1986; Srivastav and Srivastav, 1988; Srivastav and Rani, 1992).

\section{Materials and Methods}

Freshwater snakes (both sexes) of the species N.piscator (body wt 90-120 g) were collected locally toward the end of October and acclimatized under laboratory conditions for 1 week prior to use. An initial sampling of blood (from 6 specimens) was taken prior to the start of the experiment (zero hour). The remaining animals were then divided into two groups (A and B) of 30 specimens each. The specimens from both the groups were given daily intraperitoneal injections of the following treatments for 15 days:

Group A: $0.1 \mathrm{ml} / 100 \mathrm{~g}$ body wt of vehicle $(0.8 \%$ $\mathrm{NaCl})$

Group B: 10 I.U. $/ 100 \mathrm{~g}$ body wt of ovine prolactin (dissolved in $0.8 \% \mathrm{NaCl}$ )

In all cases, the injection volume was $0.1 \mathrm{ml} / 100 \mathrm{~g}$ body wt. The animals were not fed during the experiment.

Six specimens from each group were anesthetized with ethyl ether $4 \mathrm{~h}$ after the last injection on the $1 \mathrm{st}, 3 \mathrm{rd}, 5 \mathrm{th}, 10 \mathrm{th}$ and 15 th day of the experiment. Blood samples were collected by caudal amputation and analysis of serum calcium was performed according to Trinder's (1960) method.

The ultimobranchial bodies and parathyroid (rostral and caudal) glands (for location of these glands, see Srivastav and Rani, 1992) were extirpated and fixed in aqueous Bouin's solution. The tissues were routinely dehydrated in graded series of alcohols, cleared in xylene and embedded in paraffin. Sections were cut at $6 \mu \mathrm{m}$ and stained with hematoxylin/eosin.

Nuclear (ultimobranchial and parathyroidal) indexes (maximal length and maximal width) were determined (50 nuclei were measured per animal, thus 300 nuclei were measured from 6 specimens) by means of an ocular micrometer and then the nuclear volumes were calculated as

$$
\text { nuclear volume }=4 / 3 \pi \mathrm{ab}^{2}
$$

where $a$ is the major semiaxis and $b$ is the minor semiaxis. 
The differences between control and experimental values were tested for statistical significance using Student's t test.

\section{Observations}

Prolactin administration to $N$.piscator causes no effect on the serum calcium level on day 1 (Fig. 1). By day 3, the serum calcium levels are elevated and continue to increase until day 5 . Thereafter, the levels tend to decline on day 10 and day 15 (Fig. 1).

In vehicle-injected snakes the ultimobranchial body consists of compact cell clumps and follicle (Plate 1, A) which are enveloped by a connective tissue sheath with many blood capillaries. In the compact cell clumps, the cells are all alike possessing ovoid nuclei with dense chromatin material. The cytoplasm stains homogeneously with eosin. The follicular epithelium is simple possessing either cuboidal, low columnar or squamous cells. Ciliated cells are also noticed. The follicular lumen is either empty or filled with either homogeneous or heterogeneous eosinophilic colloid-like material.

The first perceivable change in the ultimobranchial body of prolactin treated specimens has been noticed on day 5 when the gland becomes active which is evident by a decreased staining response of the cytoplasm (Plate 1, B) and an increased nuclear volume (Fig. 2) of the ultimobranchial cells. From day 10 to day 15 the nuclear volume records a progressive increase (Fig. 2). A few completely exhausted cells and certain degenerating cells have also been encountered (Plate 2, A).

In vehicle-injected snakes, two pairs of parathyroid glands (one pair of the rostral and one pair

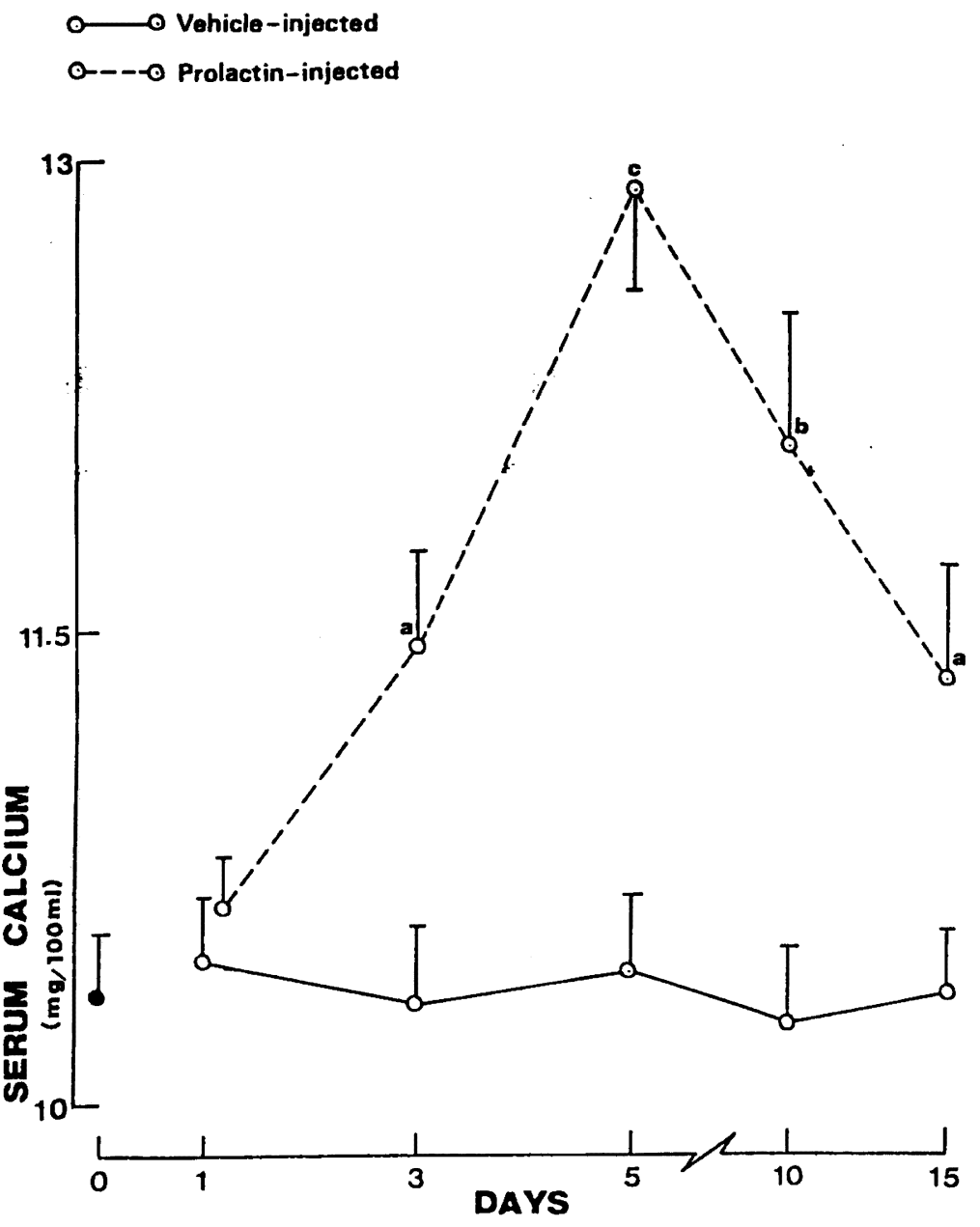

Fig. 1. Serum calcium levels of $N$. piscator after administration of vehicle or prolactin. Values are mean \pm S.E. of six specimens. $a, b$ and $c$ indicate significant differences from vehicle-injected group: $\mathrm{P}<0.05, \mathrm{P}<0.02$ and $\mathbf{P}<0.001$, respectively. 


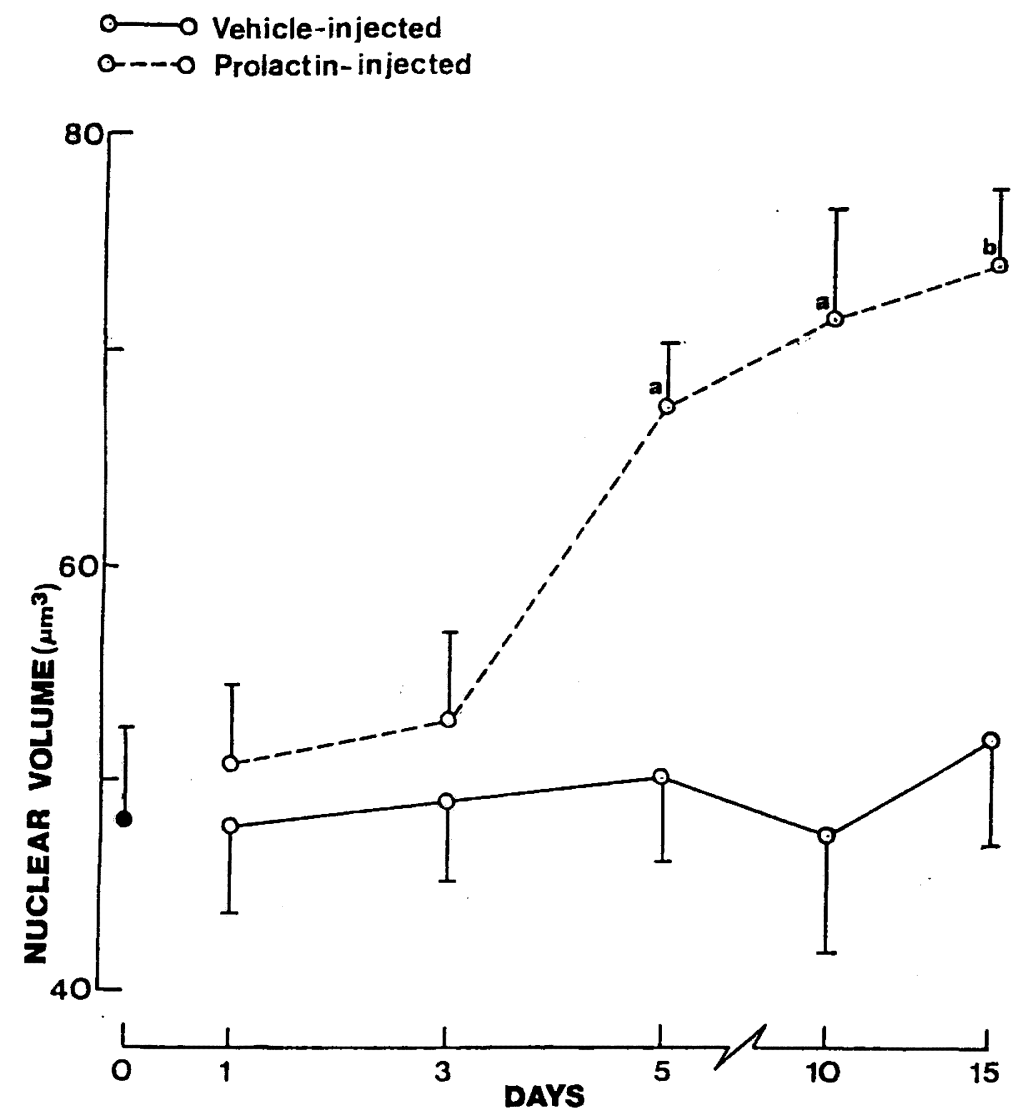

Fig. 2. Nuclear volume of ultimobranchial cells of $N$. piscator following administration of vehicle or prolactin. $a$ and $b$ indicate differences from the vehicle-injected group: $\mathrm{P}<0.01$ and $\mathrm{P}<0.005$, respectively.

of caudal parathyroid) have been located. In few specimens, accessory parathyroid glands have also been encountered. The caudal (Plate 2, B) and rostral (Plate 2, C) parathyroid glands of vehicleinjected snakes are composed of cells which are arranged in compact cords having connective tissue and blood capillaries lying between the cords. The parathyroid glands are characterized by the presence of a single cell type possessing indistinct cell boundary, scanty cytoplasm and large nucleus with dense chromatin granules. The occurrence of follicles have also been noticed in the parathyroid glands. These follicles occur frequently in the rostral parathyroid glands but occasionally in the caudal parathyroids.

The caudal parathyroid glands of prolactininjected snakes do not show any change up to day 3 . After day 5, the nuclear volume exhibits a decrease (Fig. 3). On day 10, the nuclear volume further decreases and the staining response of the nuclei decreases (Plate 3, A). After day 15, the nuclear volume is almost similar to the value of vehicleinjected specimens (Fig. 3). However, few degener- ating cells have been noticed (Plate $3, \mathrm{~B}$ ).

The rostral parathyroid gland of prolactin-treated snakes remains unchanged up to day 3 . On day 5 , a decrease in the nuclear volume has been recorded but the change is insignificant (Fig. 3). The nuclear volume records a significant decrease on day 10 which is followed by a slight increase on day 15 (Fig. 3).

\section{Discussion}

Administration of prolactin to N.piscator evoked an increased level of serum calcium. This is in agreement with the report of Swarup et al. (1985) who were the first to report the hypercalcemic effect of prolactin in a lizard, Varanus flavescens. Similar effects of prolactin have also been reported for mammal (Robinson et al., 1975), bird (Baksi et al., 1978), amphibians (Baksi et al., 1978; Srivastav and Rani, 1991a) and teleosts (Pang, 1981; Wendelaar Bonga and Flik, 1982, 1984; Srivastav and Swarup, 1985). 

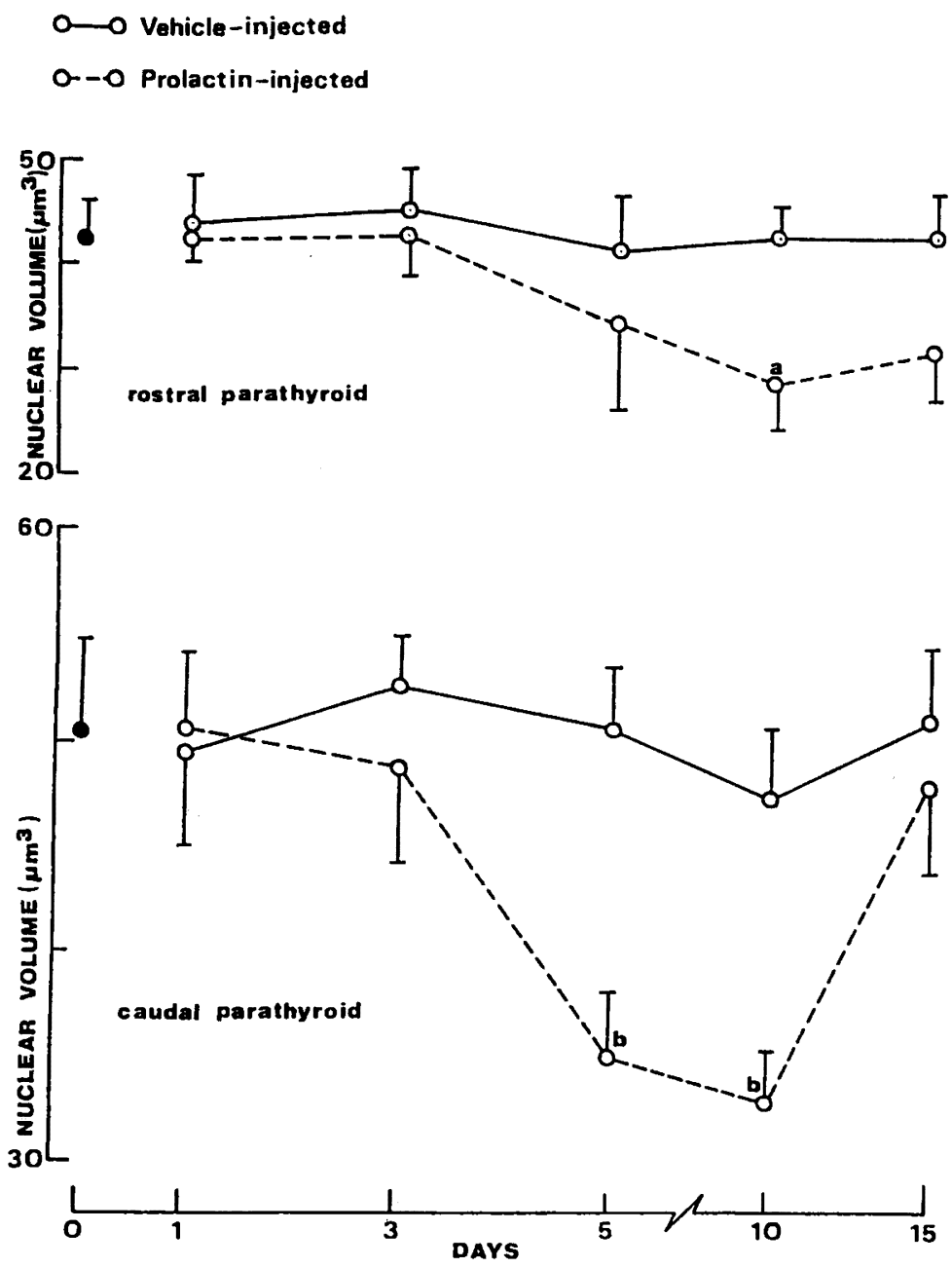

Fig. 3. Nuclear volume of caudal and rostral parathyroidal cells of $N$. piscator following administration of vehicle or prolactin. $a$ and $b$ indicate significant differences from the vehicle-injected group: $\mathrm{P}<0.05$ and $\mathrm{P}<0.01$, respectively.

The ultimobranchial gland of $N$.piscator responds to prolactin administration by expressing an increased nuclear volume and decreased staining response of cytoplasm. The hyperactivity of the gland seems to be due to elevated serum calcium level noticed after prolactin treatment. The fall in serum calcium level on day 10 and day 15 in the present study can be attributed to the hyperactivity of ultimobranchial gland which secretes more hypocalcemic factor to combat the hypercalcemic challenge. The effect of prolactin on ultimobranchial body of reptiles has not been studied earlier. However, there exists a few reports from fish (Srivastav and Swarup, 1985) and amphibia (Boschwitz, 1969; Srivastav and Rani, 1991a) which indicate the activity of ultimobranchial gland in response to prolactin treatment.

The parathyroid (caudal and rostral) glands of
$N . p i s c a t o r$ get inactivated following prolactin treatment. This response could be correlated with the increased calcium level which suppresses the release of parathyroid hormone and thus the parathyroidal cells become inactive. Degeneration of parathyroid gland has also been reported from other vertebrates after experimental hypercalcemia induced either by vitamin D administration (Swarup and Srivastav, 1979; Koyama et al., 1984; Srivastav and Rani, 1991b, 1992) or prolactin administration (Srivastav and Rani, 1991a) The present study is the first report from reptiles regarding the effects of prolactin on ultimobranchial body and parathyroid gland.

\section{Acknowledgments}

The authors are thankful to Dr. Nancy B. Clark 
of the University of Connecticut for providing suggestions on the earlier draft of this study and also to the National Hormone and Pituitary Program, U.S.A. for the gift of prolactin.

\section{Literature Cited}

1) Baksi SN, Kenny AD, Galli-Gallardo SM, Pang PKT. Vitamin D metabolism in bullfrogs and Japanese quail: Effects of estradiol and prolactin. Gen. Comp. Endocrinol., 1978;35:258-262.

2) Boschwitz $D$. Influence of prolactin on the ultimobranchial bodies of Bufo viridis. Israel J. Zool., 1969;18:277-289.

3) Flik G, Fenwick JC, Kolar Z, Mayer-Gostan N, Wendelaar Bonga SE. Effects of ovine prolactin on calcium uptake and distribution in the freshwater cichlid teleost fish, Oreochromis mossambicus. Am. J. Physiol., 1986;250:161-166.

4) Koyama T, Makita T, Enomoto M. Parathyroid morphology in rats after administration of active vitamin $D_{3}$. Acta Pathol. Jpn., 1984;34:313-324.

5) Olivereau M, Olivereau J. Action de la prolactine chez L'anguille intacte et hypophysectomisee. IV. Structure histologique de l'interrenal et metabolisme hydrominerale. Z. Vergleich. Physiol., 1970;68:429-445.

6) Olivereau M, Olivereau J. Prolactin, hypercalcemia and corpuscles of Stannius in seawater eels. Cell Tissue Res., 1978;186:81-96.

7) Olivereau M, Olivereau J. Kinetics of response of prolactin cells to environmental changes in the eel. Acta Zool. (Stockh.), 1982;63:239-245.

8) Olivereau M, Olivereau JM, Aimar C. Influence of deionized water supplemented or not with different ions on prolactin cell activity and osmotic regulation in the gold-fish. Comp. Biochem. Physiol. (A),1982;71:11-16.

9) Olivereau M, Chambolle P, Dubourg P, Olivereau J. Cytological and ultrastructural changes in the pituitary pars distalis of the goldfish kept in calcium-free environments. Biol. Cell, 1986;57:77-88.

10) Pang PKT. Hypercalcemic effects of ovine prolactin on intact killifish, Fundulus heteroclitus, subjected to different environmental calcium challenges. Gen. Comp. Endocrinol., 1981;43:252-255.

11) Pang PKT, Schreibman MP, Balbontin F, Pang RK.
Prolactin and pituitary control of calcium regulation in the killifish, Fundulus heteroclitus. Gen. Comp. Endocrinol., 1978;36:306-316.

12) Robinson CJ, Mahajan KK, Harrobin DF. Some effects of prolactin on calcium metabolism. J. Endocrinol. 1975; 65:27.

13) Srivastav Ajai K, Rani L. Prolactin-induced hypercalcemia and hyperphosphatemia in the freshwater snake, Natrix piscator. Canadian J. Zool., 1990;68:2702-2704.

14) Srivastav Ajai K, Rani L. Response of ultimobranchial body, parathyroid glands, serum calcium and serum phosphate in the frog, Rana tigrina after prolactin administration. European Archives Biology, 1991a;102:159-163.

15) Srivastav Ajai K, Rani L. Response of ultimobranchial body and parathyroid gland of the frog, Rana tigrina to administration of various vitamin $D$ analogs. European Archives Biology, 1991b:102:153-158.

16) Srivastav Ajai K, Rani L. Ultimobranchial body and parathyroid glands of the freshwater snake Natrix piscator in response to vitamin $D_{3}$ administration. J. Exp. Zool., 1992;262:255-262.

17) Srivastav Ajai K, Srivastav SP. Corpuscles of Stannius of Clarias batrachus in response to 1,25-dihydroxyvitamin $\mathrm{D}_{3}$ administration. Zool. Sci., 1988;5::197-200.

18) Srivastav SP, Swarup K. Structure and behaviour of the corpuscles of Stannius, the ultimobranchial gland and the prolactin cells in response to prolactin-induced hypercalcemia in male catfish, Clarias batrachus (L.). Monit. Zool. Ital., 1985;19:111-120.

19) Swarup K, Srivastav Ajai K. Studies of calcitonin cells and parathyroid gland of the house shrew, Suncus murinus in response to experimental hypercalcemia. Z. Mikrosk. Anat. Forsch., 1979;93:343-352.

20) Swarup K, Srivastav SP, Srivastav Ajai K, Srivastav SK. Calcemic response of Varanus flavescens to prolactin administration. J. Physiol. (Paris), 1985:80:42-43.

21) Trinder P. Colorimetric microdetermination of calcium in serum. Analyst, 1960;85:889-894.

22) Wendelaar Bonga SE, Flik G. Prolactin and calcium metabolism in a teleost fish, Sarotherondon mossambicus. In: Comparative Endocrinology of Calcium Regulation. Oguro C Pang PKT, eds. Japan Sci. Soc. Press, Tokyo, pp. 19-26.

23) Wendelaar Bonga SE, Flik G. Hypcrcalcemic control in the lower vertebrates. Calcif. Tissue Int. Suppl., 1984: 36:11-14. 
Plate I
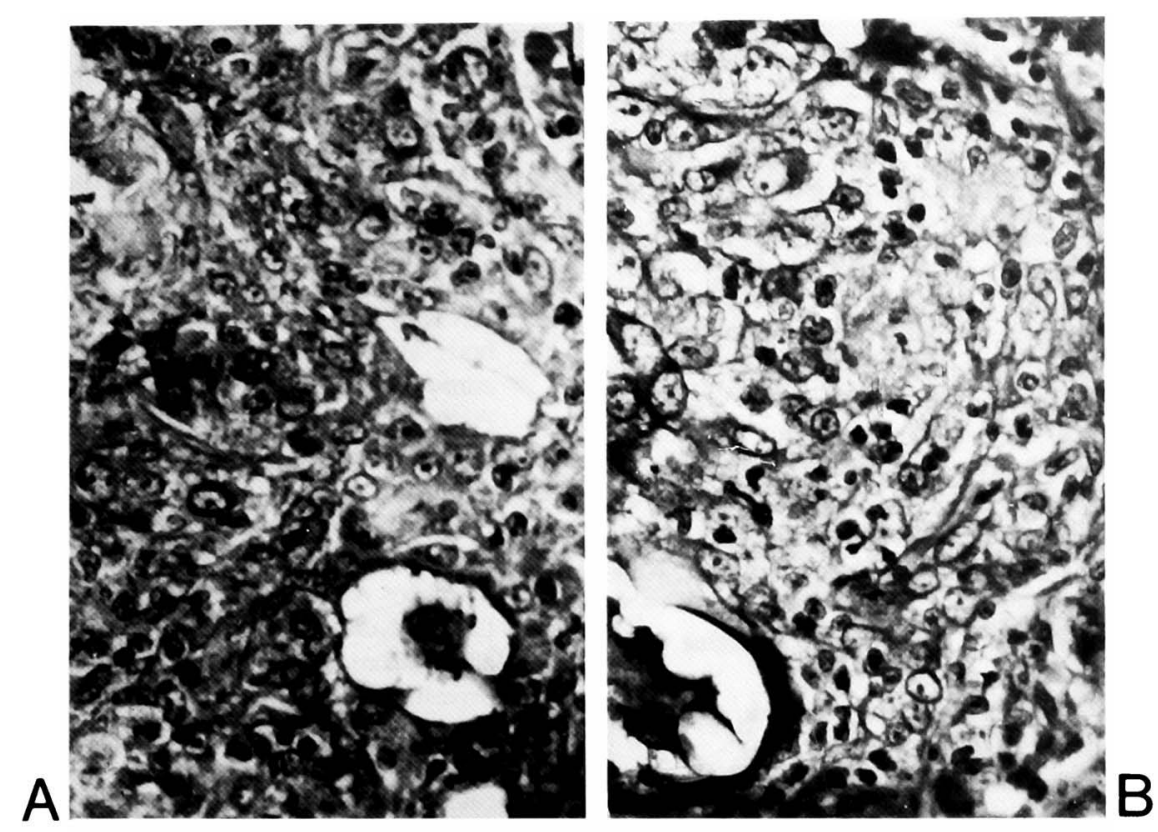

\section{Explanation of Figures}

\section{Plate I}

A. Ultimobranchial body of vehicle-injected $N$. piscator. Hematoxylin-eosin $\times 400$.

B. Ultimobranchial body of 5 days prolactin-treated snake showing decreased staining response of the cytoplasm. Hematoxylin-eosin $\times 400$. 


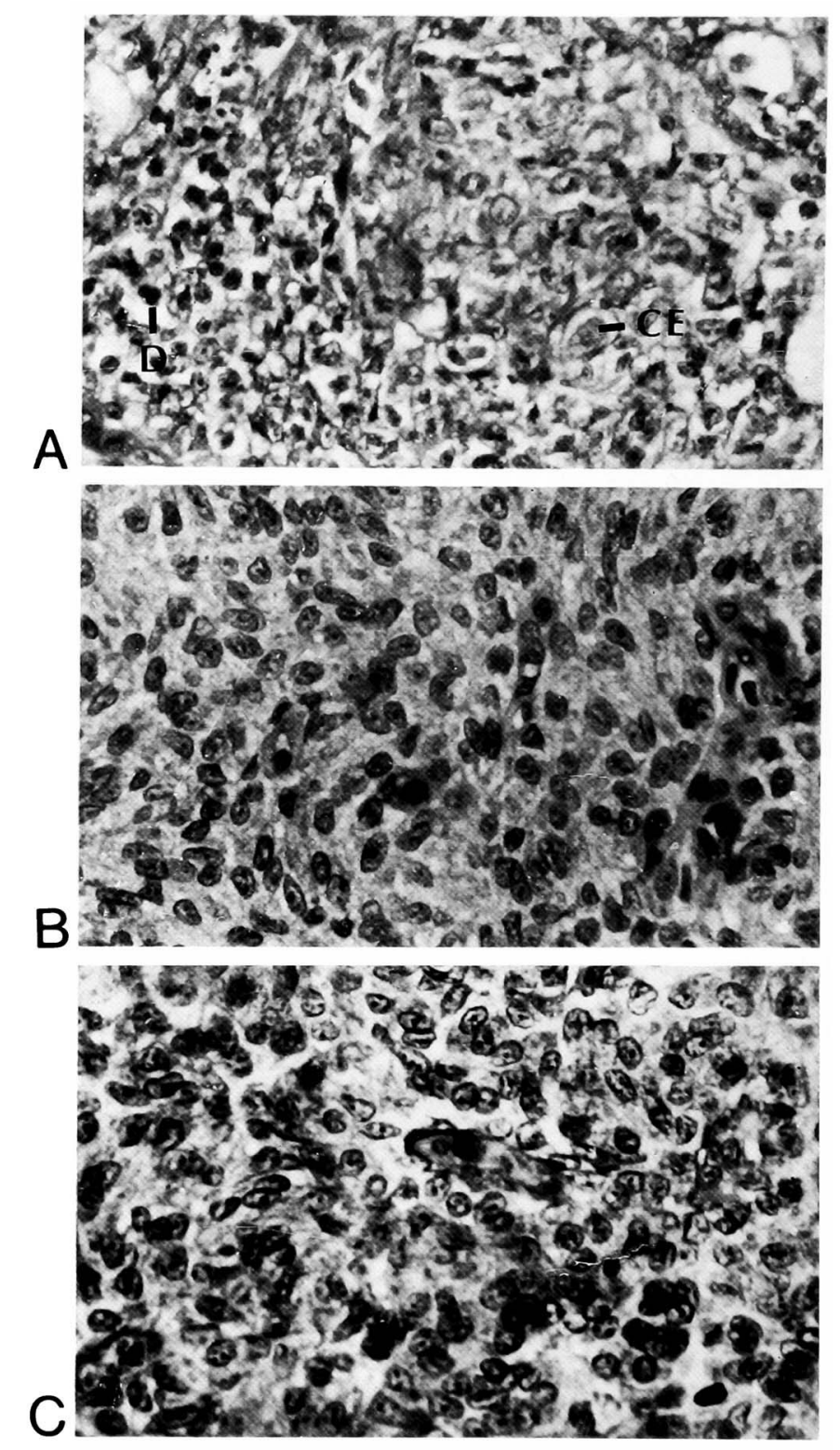

Plate II
A. Ultimobranchial body of 15 days prolactin-treated $N$. piscator. Note completely exhausted cells (CE) and degenerating cells (D). Hematoxylin-eosin $\times 400$.
B. Caudal parathyroid gland of vehicle-injected. $N$. piscator. Hematoxylin-eosin $\times 400$.
C. Rostral parathyroid gland of vehicle-injected $N$.piscator. Hematoxylin-eosin $\times 400$. 
Plate III

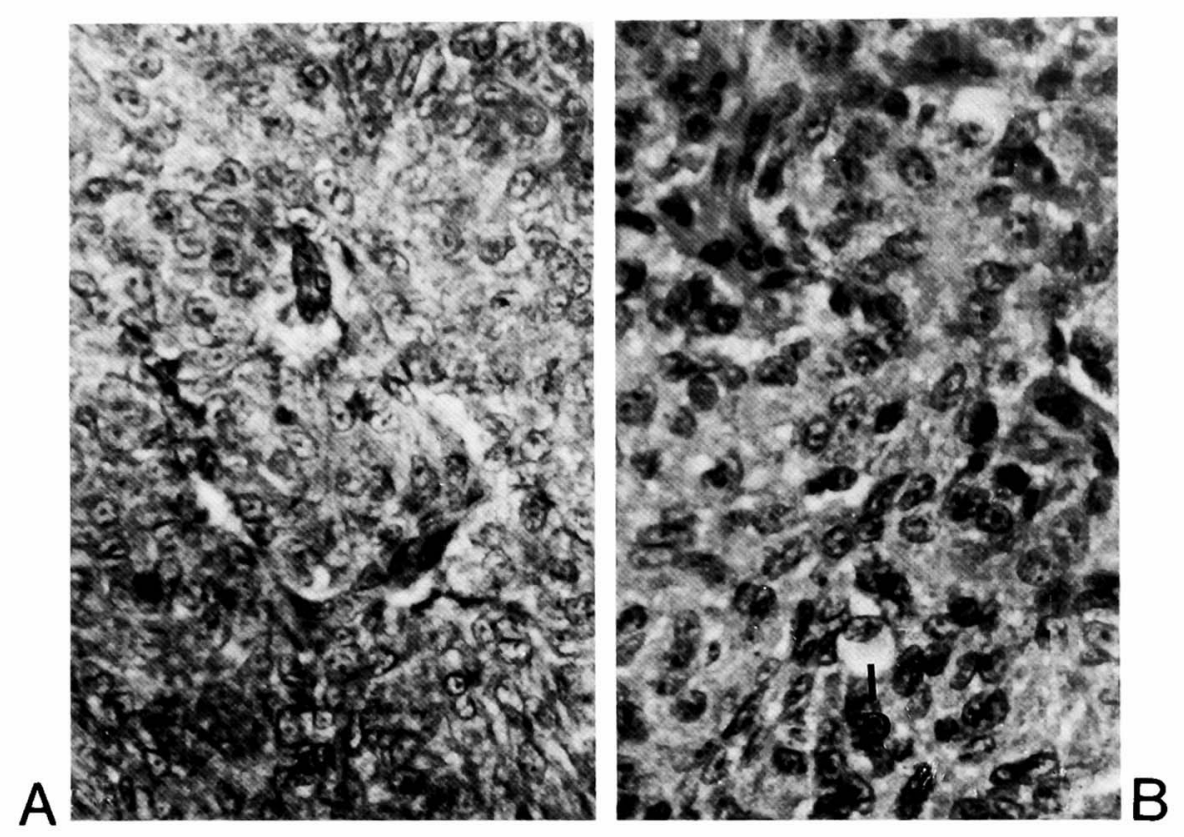

Plate III

A. Caudal parathyroid gland of 10 days prolactin-treated specimen. Note decreased staining response of nuclei. Hematoxylin-eosin $\times 400$.

B. Degenerating cells (D) in the caudal parathyroid gland of 15 days prolactin-treated $N$. piscator. Hematoxylin-eosin $\times 400$. 